\title{
THE ROLE OF ENTERPRISE MODELLING IN VIRTUAL ENTERPRISES
}

\author{
Sobah Abbas Petersen \\ Dept. of Computer and Information Science, Norwegian University of \\ Science and Technology, Trondheim, NORWAY \\ Email:sap@idi.ntnu.no
}

\begin{abstract}
The partners of a Virtual Enterprise are selected based on how well they meet the skills requirements to fill a specific role. Enterprise Modelling is a suitable means of supporting this, first by defining the Virtual Enterprise and the skills requirements of the partners and second, by using the information in the model to drive the partner selection process. The enterprise model provides information about the requirements of the partners as input to any system that supports the selection of partners. Once the partners are selected, the system can provide information about those partners back to the enterprise model. This is illustrated using a case study and by creating an enterprise model using a commercially available modelling environment.
\end{abstract}

\section{INTRODUCTION}

Enterprise models have played a central role in the design of enterprises and the management of the business processes of enterprises. With advances in distributed information technology and the ever-changing needs of the global business environment, enterprises have been challenged to adopt agile and flexible organisation models to be able to adapt to the dynamic business environment. Enterprise modelling has become a significant part of supporting enterprises' success in such an environment.

Virtual Enterprises (VEs) is a means of meeting the new challenges. While there are several descriptions of a VE, (e.g. [2], [6] and [16]), the project-based view of a VE, [1], is considered in this paper. A VE is defined as a team of partners that collaborate to achieve a specific goal.

Enterprise modelling has long been used to understand and represent traditional enterprises and their behaviours, [15] and [3]. While enterprise modelling plays a significant role in traditional enterprises, its role becomes even more important in VEs. Unlike traditional enterprises that are established and continue to exist over a long period of time, VEs are established to answer more contingent needs and can have a shorter span of life. Due to the dynamic and flexible nature of VEs, there is a greater need to build models to help understand them and their evolution. Enterprise 
models provide the support that is required in the design and analysis of VEs and the interactions within a VE and they are powerful tools for analysing and understanding the flexible nature of VEs.

VEs have a shorter lifespan and for them to succeed, they need to be formed as quickly as possible. The need for the rapid formation of VEs has been emphasized and support for this have been proposed by reference architectures and frameworks, an example of one is VERAM (VE Reference Architecture and Methodology). VERAM identifies modelling as one of its key components, which can be used to describe and capture a VE, [17].

An overview of approaches and techniques for modeling a VE is provided in [7]. One of the early examples of applying enterprise modeling to describe VEs is TOVE (Toronto Ontology for VEs), [4], where they defined a formal model to describe the goals, activities and other components of an enterprise. A goal and actor-oriented "intentional" organisation model is presented in [5]. The notion of Active Knowledge Modelling (externalisation of enterprise aspects) is used in [9] to model a VE.

In this paper, we illustrate how enterprise modelling can be used to support VEs in the various phases of their lifecycles, by presenting a case study. A commercially available enterprise modelling environment is used. The rest of this paper is organised as follows; the model of a VE and the modelling approach that is used is described in Section 2. Section 3 describes the case that will be used to illustrate how the model of the VE can be created as an enterprise model using a commercially available modelling environment. Section 4 presents the enterprise model and illustrates the advantages of having such a model.

\section{MODELLING VIRTUAL ENTERPRISES}

A VE can be described as an entity that has a goal or a set of goals that need to be achieved. An example of such a VE is a project team. The VE is formed to achieve the goals of the VE. Thus, the VE needs "partners" that need to perform some work to achieve the goals. A VE can be modelled as an entity that has a goal (and subgoals) that need to be achieved by some activity (or activities). The activities are performed by a role which is filled by a "partner" that meets certain skills requirements. A partner, in this case can be a person or'an organisation. Such a model of a VE is shown in Figure 1. The model can be described using first order logic, see [13] for details. It can also be considered as a VE ontology, such as TOVE, [4], and the Edinburgh Enterprise Ontology, [14].

This model describes a VE prior to its formation. The model helps identify the work that needs to be done by the $\mathrm{VE}$ and the types of partners that are required to perform the work. Consider a VE from a lifecycle perspective. A very simplified lifecycle of a VE can be assumed to have the main phases, design, formation and operation, see Figure 2. The model shown in Figure 1 can be created before the VE is formed and used to support the formation phase of the VE. One of the main activities during the formation phase is the selection of partners for a VE; i.e. to 
match partners to the requirements for the roles. Once the VE is formed, the information about the partners that fill the roles of the VE can be modelled, thus providing information to complete the model of the VE.

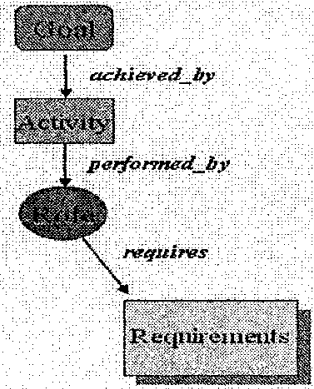

Figure 1: Enterprise Model of a Virtual Enterprise

\begin{tabular}{l|c|c|c}
$\begin{array}{c}\text { Model is } \\
\text { CREATED }\end{array}$ & $\begin{array}{c}\text { Model PROVIDES INPUT } \\
\text { to the formation process }\end{array}$ & $\begin{array}{c}\text { Model is } \\
\text { UPDATED }\end{array}$ & $\begin{array}{c}\text { Lifecycle of } \\
\text { model }\end{array}$ \\
\hline VE Design & VE Formation & VE Operation Lifocycle of \\
VE
\end{tabular}

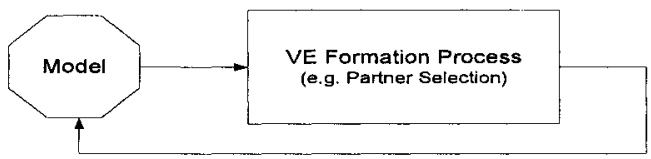

Figure 2: The Model and VE from a Lifecycle Perspective

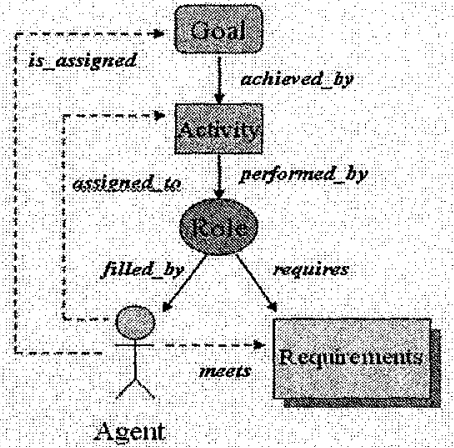

Figure 3: Model of a VE and its Partners

When information about the partners is available, additional relationships can be established in the model. For example, the model can now show the goal(s) that 
is/are assigned to any particular partner and the activity (or activities) that a partner is assigned to. See Figure 3.

\section{CASE DESCRIPTION}

Summer projects at Statoil ${ }^{1}$ are an organised form of summer jobs for university students in their $3^{\text {rd }}$ year of study. The idea is that better results are achieved by putting students together in interdisciplinary project teams. The teams work in groups of 2 to 6 students per project, for 8 weeks. The case that is modelled is "Summer project 2002 New Statoil, Use of Fibre Optics and Subsea Visualisation". The main goal was to generate ideas on how Statoil could use new technologies, such as fibre optics, to control remote production installations. 800 students applied; 75 were selected for 25 different projects. Here, each project could be considered as a VE.

Each VE is represented by its goals, the activities to achieve the goals, the roles that perform the activities and the skills that are required to fill the roles. For example, the goal of one of the projects was to explore new technologies, which could be achieved by studying different technologies and by selecting one. This activity can be performed by a group of technologists that have skills in cybernetics, telecoms technology, process control and physical electronics.

\section{MODELLING THE CASE}

The projects were well-defined. Thus, Statoil was able to identify the types of skills that they required, i.e. they could identify the requirements for the roles in the VE. Although the projects were well-defined, due to the nature of the work that was required of the students, the activities and roles were defined at a high-level.

\subsection{Modelling Environment}

The Metis modelling environment, by Troux Technologies AS, Norway, has been used. Metis provides a graphical modelling environment with powerful visualisation and analysis capabilities. It is based on Active Knowledge Modelling, [8]. The models are created using objects to represent the entities in the example and by creating relationships among these entities. For example, the activities of a VE can be represented as process objects and related to goal objects. Additional information on Metis is available from [10].

\subsection{Model of the Virtual Enterprise}

The high-level information provided by Statoil has been used in the model shown in Figure 4. The goals of the VE are represented as goal objects, activities as processes, roles as role objects and skills that are required to fill the roles are represented as requirement objects. The relationships among these entities are the lines (or arrows)

\footnotetext{
${ }^{1}$ Statoil ASA is an integrated oil and gas company. Statoil Research Centre in Trondheim Norway organises summer projects for university students to work as teams.
} 
in the figure. For example, a goal is achieved by an activity, an activity is performed by a role and the role has skills requirements.

The model shown in Figure 4 represents the model of the VE during the design phase of the VE, prior to its formation. The goals, roles and the requirements for the roles are important during the formation of the $\mathrm{VE}$, to select the appropriate partners for the VE and assign roles to them. This information can be extracted from the model and used during the formation of the VE. For example, the formation of the VE can be supported by a system that takes this information as input and provides a list of partners. A multi-agent system that provides such capabilities is described in [11] and [12].

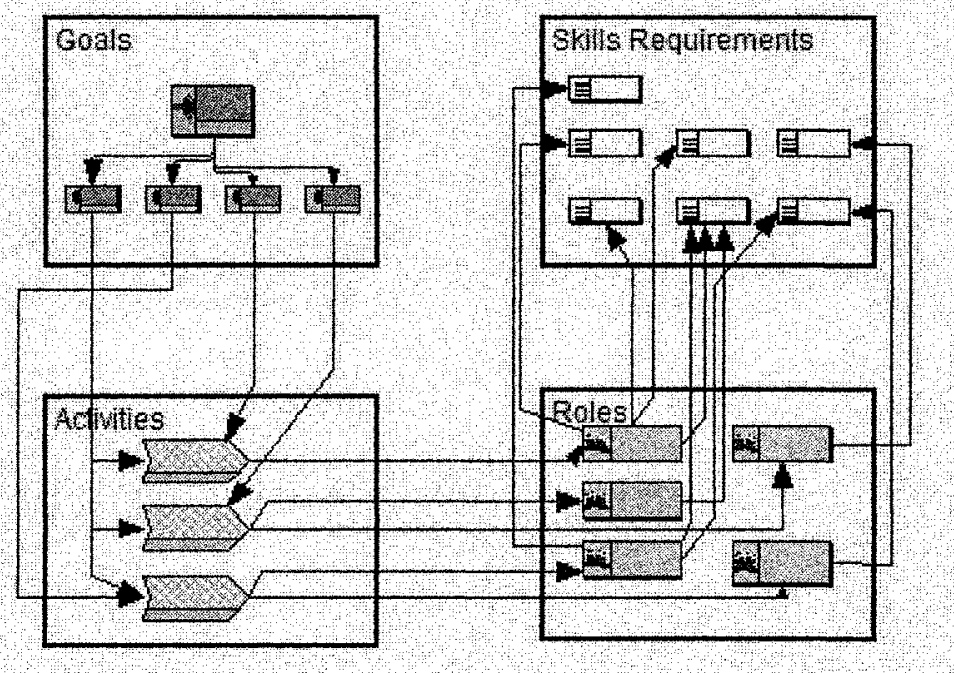

Figure 4: Model of VE Design

The list of partners and their skills can be incorporated into the model, once this is available. Figure 5 shows how the partners of the VE can be modelled and related to the roles that they fill and the skills requirements that they meet. Once the partners for the VE have been selected and modelled, additional relationships can be established between the partner objects and the rest of the model. For example, the goals that can be assigned to the partner and the activities that the partner is assigned to. This information can be obtained by tracing the relationships between the partners and roles, roles and activities and activities and goals. 


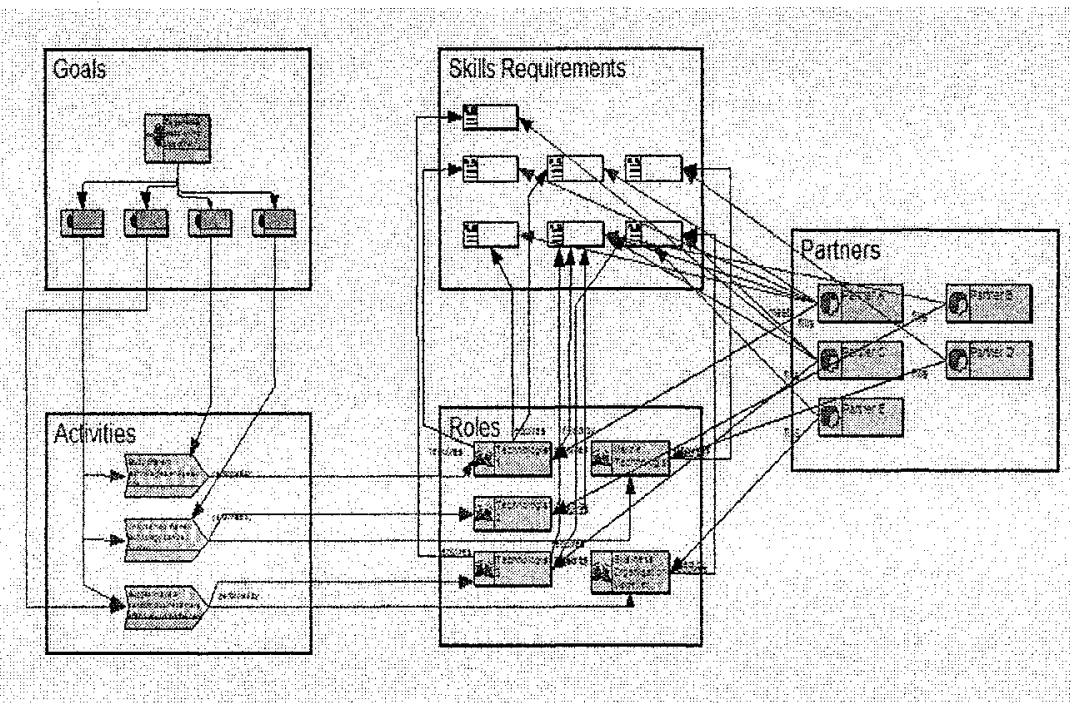

Figure 5: Model containing VE Partners

\subsection{Using the Model}

The model can be used for several purposes. As described in section 4.2, it can be used to find out which goals of the VE a partner must try to achieve by performing which activities. In addition to this, the model can also provide an overview of all the partners and their skills; see Figure 6. Similarly, the model can also be used to see the role(s) that is/are filled by a partner by meeting the requirements for the role(s); see Figure 7.

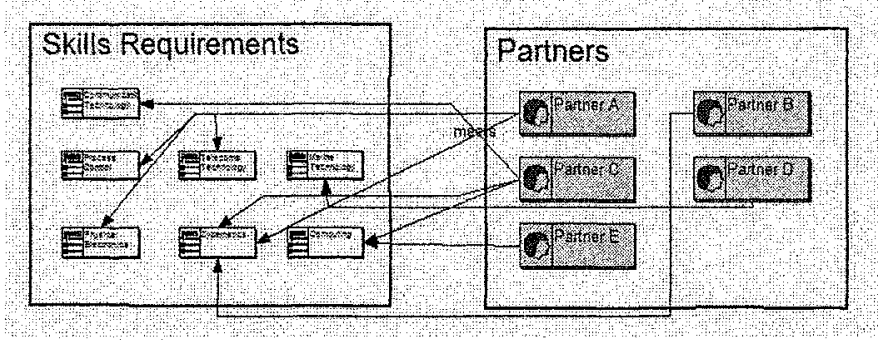

Figure 6: Overview of Partners and their Skills

The availability of an enterprise model makes it easier to ensure that all the roles in a VE are filled by partners; i.e. that the VE formation is completed. For example, if one role is unfilled by a partner or some skills requirements of a role are not met, it will be easy to detect this using the model.

Metis also provides capabilities to export information from the model, thus, making it possible to use information in the model in other systems within a company or use 
another system to perform some specialised functions using input from the model, e.g. supporting the partner selection process, [11] and [12].

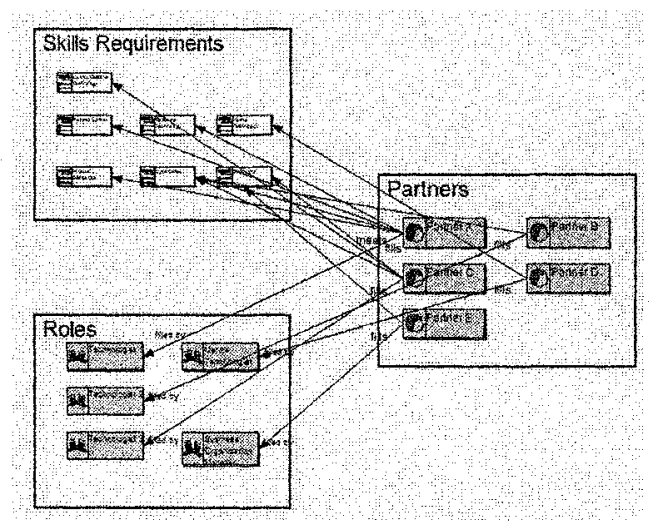

Figure 7: Roles filled by Partners

\section{CONCLUSION}

This paper describes how enterprise modelling can be used to support VEs. A VE can be described in terms of its goals, the activities that achieve the goals, the roles that perform the activities and the skills that are required to fill the roles.

The role that an enterprise model can play in the lifecycle of a VE, in particular to support its formation, is discussed. The model provides varied support during the lifecycle of a VE. A VE can be described as an enterprise model during its design phase, which helps identify the skills requirements that must be met by the partners of the VE. This information can be used in the selection of the partners and once the partners have been selected, information about the partners can be modelled, thus providing additional information about the VE and its partners. This supports in providing a more complete description of the VE.

The model can also be used to detect if the VE formation is complete, e.g. if all the roles of the VE have been filled by partners. It can also be used to identify the goals of the VE that a partner is assigned and which activities of the VE a partner should perform. Thus, the model also provide information that can be used to support the operation phase of the lifecycle of a VE.

The model presented in this paper focuses on the aspects of a VE that are relevant during the formation phase of the lifecycle of a VE. However, during the operation phase of the lifecycle, the activities can be considered from a process modelling perspective and enhanced to incorporate information for monitoring and control of the process. 


\section{ACKNOWLEDGMENTS}

I would like to thank Dag Sjong, Statoil, Norway, for providing this case and Troux Technology AS, Norway, for letting me use the Metis modelling environment for describing the case.

\section{REFERENCES}

1. Bernus, P., Bertok, P. and Nemes, L., "Modelling Dynamic Management Features of Virtual Enterprises", in Computer Applications in Production Engineering, eds. Plonka and G. Olling, Chapman and Hall, London, 1997, pp.643-655.

2. Fischer, K.,Muller, J., Hemmig, I. and Scheer, A., "Intelligent Agents in Virtual Enterprises", in Proceedings of 1st International Conference and Exhibition on the Practical Applications of Intelligent Agents and Multi-Agent Technology, April, 1996, London, U.K., pp. 205-204.

3. Fox, M.S., Gruninger, M., "Enterprise Modelling", AI Magazine, AAAI Press, Fall 1998, p. 109-121.

4. Fox, M.S., Barbuceanu, M. and Gruninger, M., "An Organisation Ontology for Enterprise Modelling: Preliminary Concepts for Linking Structure and Behaviour", Computers in Industry, Vol. 29, 1996, pp. 123-134.

5. Fuxman, A., Giorgini, P., Kolp, M. and Mylopoulos, J., "Information Systems as Social Structures", 2nd International Conference on Formal Ontologies for Information Systems (FOIS-2001), October 2001, Ogunquit, USA.

6. Garita, C. and Afsarmanesh, H., "A Study of Information Management Approaches for Support Infrastructures", Cove Newsletter, (1), 2001

7. Gastinger, A. and Szegheo, O., "Enterprise Modelling Approaches", Enterprise Modeling: Improving the Global Industrial Competitiveness, eds. A. Rolstadås and B. Andersen, Kluwer Academic Publishers, 2000, pp. 55-70.

8. Lillehagen, F. "The Foundation of the AKM Technology", Concurrent Engineering: Enhanced Interoperable Systems, eds. Jardim-Goncalves, Cha and Steiger-Garcão, Balkema, The Netherlands, 2003, pp. 700-715.

9. Lillehagen, F., Dehli, E. and Fjeld, L., "Utilising Active Knowledge Models in an Infrastructure for Virtual Enterprises", in eds. L. M. Camarinha-Matos, Collaborative Business Ecosystems and Virtual Enterprises, Kluwer Academic Publishers, pp. 353-360.

10. Metis: http:/www.trouxmetis.no

11. Petersen, S. A., Rao, J., Matskin, M. "Virtual Enterprise Formation with Agents - an Approach to Implementation", IEEE/WIC International Conference on Intelligent Agent Technology, IAT2003, Halifax, Canada, October 2003, p. 527-530.

12. Petersen, S. A., Divitini, M., "Using Agents to Support the Selection of Virtual Enterprise Teams", Proceedings of 4th International Bi-Conference Workshop on Agent-Oriented Information Systems (AOIS-2002) (at AAMAS 2002), Bologne, Italy, July 2002.

13. Petersen, S. A., Gruninger, M., "An Agent-based Model to Support the Formation of Virtual Enterprises", International ICSC Symposium on Mobile Agents and Multi-agents in Virtual Organisations and e-Commerce (MAMA 2000), in Woolongong, Australia, 11-13 Dec. 2000.

14. Uschold, M., King, M., Moralee, S. and Zorgios, Y., "The Enterrpise Ontology", Knowledge Engineering Review, Special Issue on Putting Ontologies to Use, 13, 1998.

15. Vernadat, F. B., Enterprise Modeling and Integration Principles and Applications. Chapman and Hall Publishers, 1996.

16. Vesterager, J., Larsen, L. B. and Gobbi, C., "Architecture and Methodology for Creating Virtual Enterprises" - Results from Globeman 21, Presented at the IMS Globeman 21 Open Day, Time24, Tokyo, Japan, March 1999.

17. Zweger, A., Tølle, M. and Vesterager, J., "VERAM: Virtual Enterprise Reference Architecture and Methodology", Global Engineering and Manufacturing in Enterprise Networks GLOBEMEN, eds. I. Karvonen et. al., Julkaisija Utgivare Publisher, Finland, 2002, pp. 17-38. 